\title{
EL SEXISMO COMO BLANCO DEL HUMOR EN LAS REDES SOCIALES ${ }^{1}$
}

\author{
ANA MANCERA RUEDA \\ Universidad de Sevilla
}

Recibido: $15 / 09 / 2014$

Aceptado: 24/11/2014

\section{Resumen}

Partiendo de las seis fuentes de conocimiento para la explicación del humor identificadas por la Teoría general del humor verbal, y del modelo pragmático desarrollado por el grupo GRIALE, en este trabajo se analiza un corpus de 1.526 mensajes publicados en la red social Twitter. Estos contienen una o varias etiquetas utilizadas por los internautas para denunciar el contenido sexista de las declaraciones de ciertos políticos españoles. En qué medida se sirven del humor los usuarios de esta red de microblogging para mostrar su repulsa hacia las afirmaciones de sus representantes, $o$ cuáles son los mecanismos lógicos y las principales marcas o indicadores del humor que pueden encontrarse en este tipo de mensajes son algunos de los interrogantes a los que se tratará de responder.

Palabras clave: sexismo, humor, ironía, discurso mediado por ordenador, Twitter

\begin{abstract}
On the basis on the six sources of knowledge for explanation of humor identified by the General Theory of Verbal Humor and the pragmatic model developed by the GRIALE group, in this paper, a corpus of 1,526 messages posted on the Twitter social network is analyzed. They contain one or more hashtags used by netizens to denounce

1. Este estudio se enmarca en el seno del Proyecto FFI2011-23573, «Variación y adaptación en la interacción lingüística en español», financiado por el Ministerio de Ciencia e Innovación, que desarrolla en la actualidad el grupo de investigación El español hablado en Andalucía (HUM-134). Agradecemos los valiosos comentarios de dos evaluadores anónimos sobre una versión anterior de este trabajo.
\end{abstract}

Feminismo/s 24, diciembre 2014, pp. 163-192

DOI: $10.14198 / \mathrm{fem} .2014 .24 .08$ 
the sexist affirmations of certain Spanish politicians. What porcentaje represents the use of humor in this network, or what the logical mechanisms and major brands or indicators of humor are more common in this type of messages are some of the questions that we will try to respond.

Keywords: sexism, humor, irony, computer-mediated discourse, Twitter 


\section{Introducción}

El objetivo de esta investigación es averiguar en qué medida los usuarios de la red social Twitter se sirven del humor verbal y de la ironía como estrategias para otorgar un mayor grado de difusión a sus críticas hacia determinados representantes políticos que han alcanzado notoriedad pública por la formulación de un tipo de declaraciones susceptibles de ser calificadas como sexistas. Para ello analizamos un corpus de 1.526 tuits cuya comprensión está supeditada al conocimiento de la situación comunicativa que motivó su publicación. De ahí que hayamos decidido dedicar este epígrafe introductorio a la explicación de los aspectos de la actualidad noticiosa más relevantes para la interpretación de los mensajes recopilados. A continuación, basándonos en la Teoría general del humor verbal (General Theory of Verbal Humor) (en adelante, TGHV) y en el modelo pragmático desarrollado por el grupo GRIALE para el estudio de las marcas e indicadores del humor y de la ironía, llevaremos a cabo una caracterización de los distintos tipos de tuits que pueden localizarse en nuestro corpus analítico. Por último, abordaremos un estudio cuantitativo para tratar de sopesar la representatividad de los mensajes de carácter humorístico entre todos aquellos que utilizan etiquetas como \#MachismoPSOE, \#machismoPP o \#dimisioncastelao para formular actos de amenaza a la imagen de los políticos.

A principios de julio de 2014, el Ministerio del Interior del Gobierno de España publicó en su página web una serie de consejos para prevenir una violación ${ }^{2}$. Entre ellos se encontraba el de echar «las cortinas al anochecer para evitar miradas indiscretas», o el de utilizar «silbatos para ahuyentar al delincuente». Esto suscitó la indignación de varias diputadas del Partido Socialista (PSOE), que acusaron al departamento que dirige el ministro del Partido Popular (PP) Jorge Fernández Díaz, de culpabilizar a la mujer. Las redes sociales fueron el principal medio utilizado por estas representantes

2. «Servicios al ciudadano: Prevención de la violación», Ministerio del Interior, Gobierno de España, disponible en: <http://www.interior.gob.es/web/servicios-al-ciudadano/segu$\mathrm{ridad} /$ consejos-para-su-seguridad/prevencion-de-la-violaci\%C3\%B3n>, consultado el 01-09-2014. 
para manifestar sus críticas. Por ejemplo, Susana Sumelzo, secretaria de Administraciones Públicas del PSOE, publicó el siguiente mensaje en su perfil de Twitter ${ }^{3}$ :

Susana Sumelzo (@SSumelzo). «La realidad supera la ficción: Interior recomienda cerrar las cortinas de casa para evitar violaciones http://www.eldiario. es/_11804c75_@eldiarioes».18-08-2014.Tuit.

Y a él respondieron muchos de sus seguidores con tuits como este, con los que mostraban su conformidad con sus puntos de vista:

Manuel Terrón(@manuelteher).«@SSumelzo@eldiarioes esto es de traca o ciencia ficción.Se creen que somos tontos o algo más?». 20-08-2014. Tuit.

Pero el debate sobre dicho tema adquirió repercusión en las redes sociales a raíz de una entrevista realizada por la cadena radiofónica Onda Cero a Francisco Javier León de la Riva, alcalde de Valladolid ${ }^{4}$, ciudad en la que se acababa de producir una violación. Al ser preguntado por su opinión sobre las recomendaciones del Ministerio de Interior, el edil del PP contestó lo siguiente:

«Tú piensa que entras en un ascensor y hay una chica con ganas de buscarte las vueltas. Se mete contigo en el ascensor, se arranca el sujetador o la falda y sale dando gritos de que la has intentado agredir. Por lo tanto, ojo con ese tema, que tiene doble lectura. De ida y de vuelta».

Tales declaraciones generaron gran malestar entre los internautas, muchos de los cuales se sirvieron del humor para manifestar su postura crítica. Por ejemplo, el siguiente mensaje fue enviado por la activista social Ada Colau, bien conocida por haber sido la portavoz de la Plataforma de Afectados por la Hipoteca (PAH) hasta mayo de 2014:

3. Al igual que Facebook o LinkedIn, Twitter constituye una plataforma en línea que se basa en la creación de un perfil susceptible de ser actualizado de manera periódica por medio del envío de mensajes. El enunciador puede decidir difundirlos públicamente u optar por distribuirlos solo de manera restringida entre los miembros de su círculo de contactos. Twitter se asemeja también a otras redes sociales en que sus mensajes pueden enviarse desde un sitio web o por medio de SMS, mensajería instantánea u aplicaciones creadas ad hoc para móviles. Además, de forma similar a las bitácoras, permite crear contenidos que, al tiempo que se muestran en la página del perfil del usuario, son difundidos de manera inmediata a otros internautas que han elegido la opción de recibirlos. Sin embargo, hay un rasgo que le es peculiar: sus textos no pueden exceder el límite de 140 caracteres. De ahí que suela identificársela como una plataforma de microblogging o nanoblogging, a medio camino entre las bitácoras y las redes sociales.

4. «Valladolid en la Onda. Entrevista con el Alcalde de Valladolid», Onda Cero, 21-082014. Disponible en: <http://www.ondacero.es/audios-online/emisoras/valladolid/valladolid-onda-entrevista-alcalde-valladolid-jueves-agosto_2014082100059.html>, consultado el 01-09-2014. 


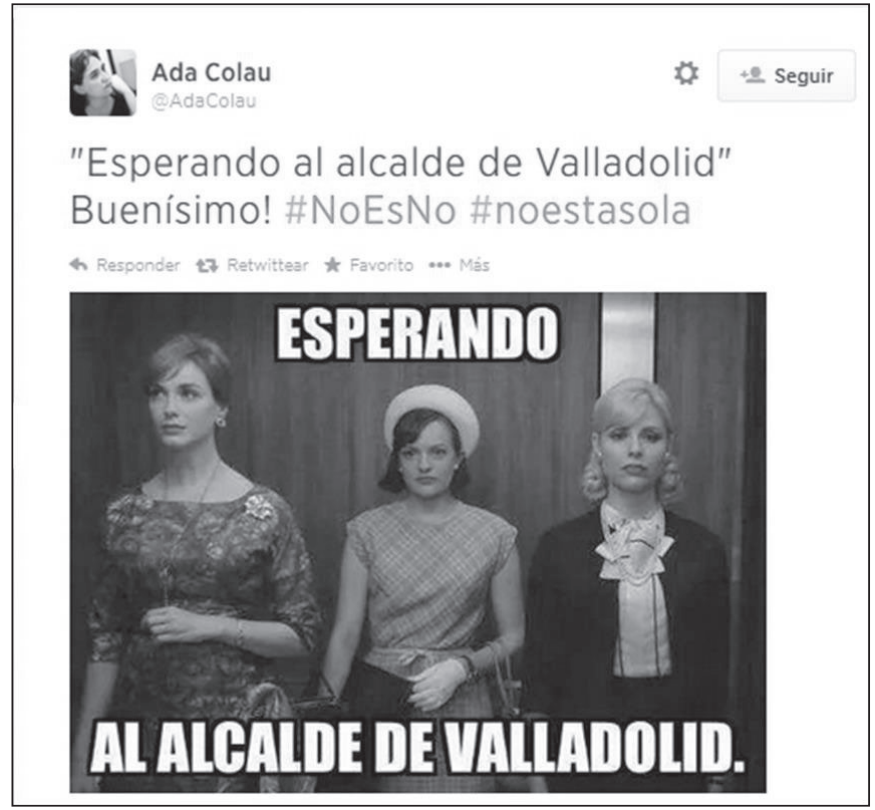

IMAGEN 1: Tuit publicado en el perfil de Twitter de Ada Colau (@AdaColau) el 22-082014. Disponible en: <https://twitter.com/AdaColau/status/502901723535773697>, consultado el 01-09-2014

A continuación, Colau manifestó su opinión de que el edil vallisoletano se merecía «una lluvia de sujetadores y zapatos de tacón» en su próximo acto público, a lo que una de sus seguidoras en Twitter respondió con una imagen de un sujetador. La activista catalana retuiteó, es decir, reenvió este mensaje a través de su propio perfil, para otorgarle mayor difusión, y añadió el hashtag 5 \#EscracheDeSujetadores, animando a otras usuarias a llevar a cabo una protesta virtual mediante la publicación de imágenes de sujetadores en sus cuentas:

5. José Luis Orihuela define el hashtag o 'etiqueta' como una palabra clave que, precedida del signo de la almohadilla (\#), sirve para identificar el tema de un mensaje. Cuando esta es utilizada de manera recurrente en un gran número de tuits durante las últimas horas puede llegar a convertirse en trending topic, es decir, en 'tema del momento' en un determinado país, o en una ciudad concreta. Orihuela, José Luis. Mundo Twitter. Barcelona, Alienta, 2011, p. 34. 


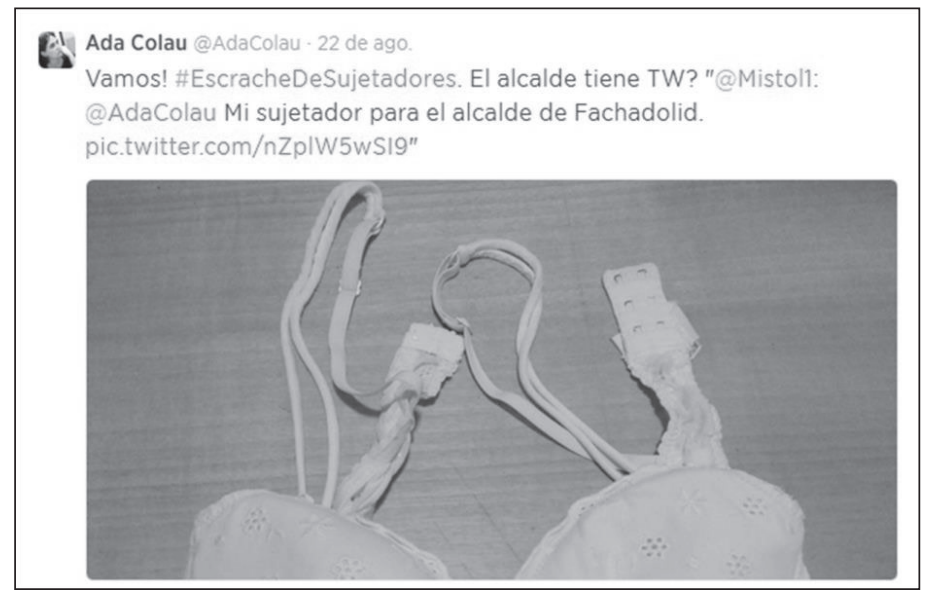

IMAGEN 2: Tuit publicado en el perfil de Twitter de Ada Colau (@AdaColau) el 22-082014. Disponible en: <https://twitter.com/AdaColau/status/502909836850626560>, consultado el 01-09-2014

Esta iniciativa tuvo una extraordinaria acogida ${ }^{6}$, pero no solo entre las usuarias, sino también entre los internautas varones, que tuitearon imágenes de su ropa interior o incluso de sujetadores que portaban sobre su torso. Además, el «escrache virtual» fue más allá de Twitter, ya que medio centenar de personas se concentró frente a la sede del consistorio de Valladolid, que fue rodeado por una cadena de sujetadores y por múltiples pancartas que abogaban «por una ciudad libre de alcaldes machistas».

No es la primera vez que el comentario sexista de un político suscita indignación en las redes sociales. Así, pocos días antes de que León de la Riva formulara sus polémicas declaraciones, el alcalde de Málaga, Francisco de la Torre, trató de defender el operativo de seguridad puesto en práctica

6. De ello se hicieron eco numerosos medios de comunicación. Cfr. por ejemplo la siguiente noticia publicada en El Mundo: «Ada Colau inicia en Twitter un \#EscracheDeSujetadores virtual contra el alcalde de Valladolid», El Mundo, 23-08-2014, disponible en: <http:// www.elmundo.es/espana/2014/08/23/53f8c77be2704e221b8b4577.html>, consultado el 01-09-2014. O esta otra, difundida por los Servicios Informativos de la cadena de televisión Telecinco: «Escrache en Twitter contra León de la Riva en el [sic] se le 'lanzan' virtualmente sujetadores», Telecinco, 23-08-2014, disponible en: <http://www.telecinco. es/informativos/sociedad/Ada-Colau-Twitter-Leon-Riva_0_1848525202.html>, consultado el 23-08-2014. 
durante la feria de su ciudad (donde presuntamente acababa de tener lugar la violación de una chica de 20 años por parte de cinco jóvenes de entre 17 y 23 $a_{n ̃ o s}{ }^{7}$ ) sosteniendo que «en España hay más de mil violaciones al año», $y$ «no se puede poner un policía detrás de cada ciudadano». Esto motivó tuits tan sarcásticos como el siguiente:

LoveWillTearUsAznar (@lwtuaznar). «Según el alcalde de Malaga, el ébola dejará de tener importancia cuando haya más de mil muertos al año. $\mathrm{O}$ algo así». 18-08-2014. Tuit.

También durante esa semana otro edil, en este caso el de Toledo, Emiliano García-Page, hizo unas afirmaciones que podrían calificarse de machistas, al manifestar su opinión de que el escándalo de los papeles del ex tesorero del PP Luis Bárcenas se había producido porque los dirigentes de este partido «no saben hacer nada sin la chacha», y «lo cierto y verdad es que no pienso que Cospedal ${ }^{8}$ sepa pasar la aspiradora». Esto le reportó numerosas críticas al secretario general de los socialistas de Castilla-La Mancha, tantas que en Twitter la etiqueta \#MachismoPSOE se convirtió en trending topic:

Ana María Saá García (@AnaSaaG). «Orgulloso de ser \#TT? García-Page (PSOE): «Yo no tengo claro que Cospedal sepa pasar la aspiradora» http:// www.cadenaser.com/espana/articulo/emiliano-garcia-page-tengo-clarocospedal-sepa-pasar-aspiradora/csrcsrpor/20140821_srcsrnac_17/Tes... \#MachismoPSOE». 22-08-2014. Tuit.

Sin embargo, no era la primera vez que dicha etiqueta cobraba protagonismo, pues ya había sido utilizada por los usuarios de Twitter para mostrar su rechazo a unas declaraciones del secretario de organización del PSOE de Huelva, Jesús Ferrera, quien ante las malas cifras de empleo dadas a conocer en marzo de 2013 afirmó que la ministra de Empleo Fátima Báñez «debería dedicarse a otra cosa», ya que a su juicio «estaría mejor en San Juan del Puerto [localidad natal de la ministra] haciendo punto de cruz». A esta descalificación respondieron los internautas con tuits como el siguiente:

7. Sin embargo, finalmente el caso fue archivado, y se liberó a los presuntos agresores. Cfr. por ejemplo la siguiente noticia: «Los jóvenes detenidos por la presunta violación en Málaga solo se sienten "seguros" en casa», La Vanguardia, 23-08-2014, disponible en: <http://www.lavanguardia.com/local/sevilla/20140823/54413952739/jovenes-violacionmalaga-casa.html>, consultado el 01-09-2014.

8. María Dolores de Cospedal, secretaria general del Partido Popular desde 2008.

Feminismo/s 24, diciembre 2014, pp. 163-192 


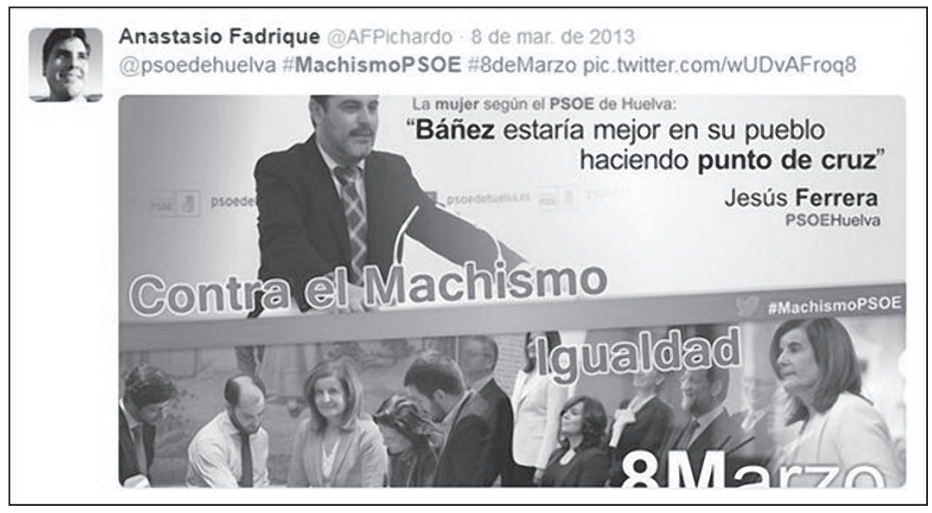

IMAGEN 3: Tuit publicado en el perfil de Twitter de Anastasio Fadrique (@AFPichardo) el 08-03-2013. Disponible en: <https://twitter.com/AFPichardo/ status/310045736899313665>, consultado el 01-09-2014

Asimismo, las palabras del presidente del Consejo General de la Ciudadanía en el Exterior José Manuel Castelao Bragaño, para quien «las leyes son como las mujeres, están para violarlas», o las del ministro de Agricultura Miguel Arias Cañete, que afirmó que «a los regadíos hay que manejarlos como a las mujeres, con mucho cuidado, que le pueden perder a uno», suscitaron en Twitter una miríada de opiniones en contra, manifestadas en mensajes que hacían uso del hashtag \#machismoPP. Dicha etiqueta fue también utilizada por los internautas para criticar a este político del Partido Popular cuando concurrió como cabeza de lista de su partido a las elecciones de 2014 al Parlamento Europeo. En esta ocasión, la causa de que su comportamiento se calificara de machista fueron las afirmaciones que realizó en el transcurso del cara a cara con Elena Valenciano, la candidata del PSOE, durante el cual sostuvo que «el debate con una mujer es difícil. Si demuestras superioridad intelectual, eres machista». Tales comentarios suscitaron gran hilaridad en las redes sociales, donde se difundieron mensajes como este:

Rosa F. Lastra (@rosaferlas). «Cañete no acierta con las palabras: dijo anoche que ganarán las elecciones como señores http://www.diariocritico.com/nacional/arias-canete/elecciones-europeas-2014/455916\#.U32QLp8noe5.twitter ... ... \#HomoCañetus \#MachismoPP». 22-08-2014. Tuit.

Adviértase el uso que se hace en el tuit precedente, de los hashtags \#MachismoPP y \#HomoCañetus. Esta última etiqueta fue utilizada también por los usuarios para criticar al candidato del PP haciendo uso tanto del humor gráfico como del humor verbal, en mensajes como el siguiente: 
No solo los representantes de los dos grandes partidos mayoritarios fueron objeto de burla en Twitter a raíz de comentarios sexistas acerca de sus colegas de otras formaciones políticas. Por ejemplo, el hashtag \#chochitodeoro surgió a raíz de las palabras publicadas en la bitácora personal de un concejal del Bloque Nacionalista Gallego en Cambados (Pontevedra), Xaquín Charlín González, quien se refirió a la vicepresidenta del Gobierno con el sobrenombre de «chochito de oro», tras difundirse en los medios de comunicación que el contrato para sus reconocimientos ginecológicos financiado con dinero público ascendía supuestamente a 40.000 euros. El rechazo que tal

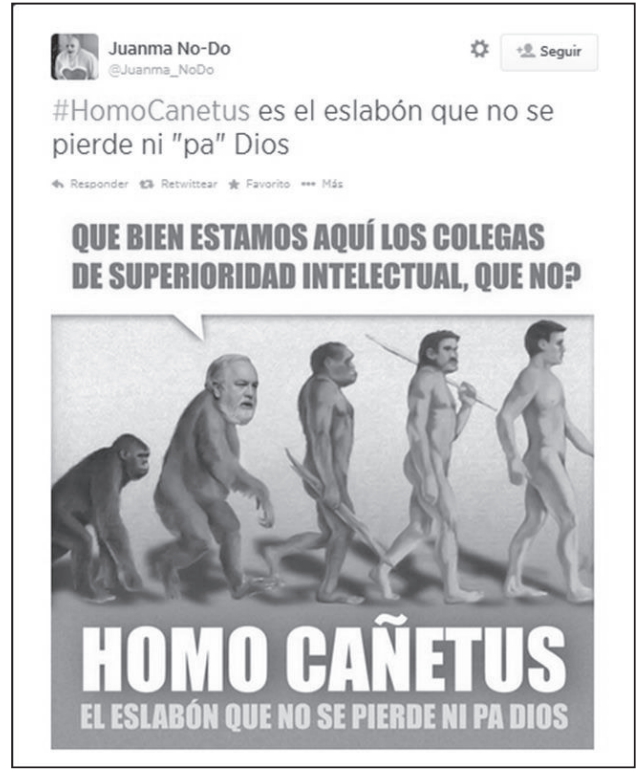

IMAGEN 4: Tuit publicado en el perfil de Twitter de Juanma No-Do (@Juanma_ NoDo) el 16-05-2014. Disponible en: <https://twitter.com/Juanma_NoDo/ status/467340537314676737>, consultado el 01-09-2014 aseveración suscitó en las redes sociales se trasladó a la opinión pública fuera del ámbito digital, y finalmente el político tuvo que dimitir:

Alfonso (@alfonsojag). «@mbdc76 según he visto, ha dimitido el autor perteneciente a la derecha rancia (o es del BNG) del \#ChochitoDeOro». 11-062013. Tuit.

Por último, entre los mensajes de Twitter que vamos a estudiar en las páginas siguientes se encuentran aquellos en los que se hace uso de la etiqueta \#ToniCantóFacts para criticar al portavoz de UPyD en la Comisión de Igualdad del Congreso de los Diputados, a raíz de la publicación del siguiente tuit:

Toni Cantó (@Tonicanto1). «La mayor parte de las denuncias por violencia de género son falsas. Y los fiscales no las persiguen. Las estadísticas son sesgadas». 25-02-2013. Tuit. 
Algo que suscitó una serie de reacciones en contra, manifestadas en su mayoría en un tipo de comunicación non bona fide $e^{9}$ caracterizada, como veremos, por el uso del humor verbal:

Libertad (@Sahakiel). «El maltrato a la mujer son los padres \#tonicantofacts». 25-02-2013. Tuit.

Hay que tener en cuenta que el número de mensajes que emplea una determinada etiqueta está sometido a fluctuaciones considerables motivadas por la actualidad noticiosa. Por ejemplo, en agosto de 2014, a raíz de los intentos del gobierno español por lograr que Miguel Arias Cañete fuera designado comisario de la Unión Europea, muchos internautas, para establecer un «hilo de conversación ${ }^{10}$ en torno a dicho asunto de la actualidad noticiosa, volvieron a recurrir a la etiqueta \#HomoCañetus, que no había vuelto a ser utilizada prácticamente desde los comicios europeos del 20 de mayo:

Pilar L. (@Maxuxta).«\#HomoCanetus, el superior, no será comisario. http:// www.infolibre.es/noticias/politica/2014/08/26/el_complicado_que_canete_ sea_nominado_para_una_comisaria_economica_20862_1012.html ... Que se dedique a sus negocios». 26-08-2014. Tuit.

Con ello queremos mostrar cómo algunas etiquetas están sujetas a un uso más dilatado a lo largo del tiempo. Este es el caso también de \#machismoPP, \#machismoPSOE o \#ToniCantóFacts. Por ejemplo, la parodia del parlamentario de UPyD parece haberse convertido en uno de los pasatiempos favoritos de los usuarios de Twitter, algo que atestiguan mensajes como el siguiente:

NuevasDegeneraciones (@nn_dgg). «Es pronto para un \#ToniCantóFacts o hay que retomar las cosas que son ETA o \#CulpaDelComunismo?». 12-012013. Tuit.

\section{Corpus y metodología}

Nuestro estudio se fundamenta en el análisis de un total de 1.526 tuits que contienen alguna de las siguientes etiquetas: \#machismoPSOE, \#machismoPP, \#MachismoARV, \#chochitodeoro, \#dimisioncastelao, \#CastelaoDimision,

9. RASKIN, Victor. Semantic Mechanisms of Humor. Reidel, Dordrecht, 1985.

10. Las palabras contenidas en la etiqueta suelen indicar el tema del tuit, lo que Tíscar Lara asocia a una «función discursiva». Gracias a la etiqueta es posible «coser hilos de conversación, recapitular ideas, tejer conversaciones alrededor de un tema determinado e incluso entrar espontáneamente en conversaciones ajenas con el simple uso de su misma palabra clave». LARA, Tíscar. "Twitter y sus funciones comunicativas». Tíscar.com, 13-02-2012. Disponible en: <http://tiscar.com/2012/03/11/twitter-y-susfunciones-comunicativas/>, consultado el 15-09-2014. 
\#HomoCañetus, \#ToniCantóFacts, \#escrachedesujetadores, \#EscracheDeSujetadores ${ }^{11}$. Con el objeto de averiguar en qué medida los internautas se sirven del humor verbal para denunciar las declaraciones de carácter sexista formuladas por los políticos antes mencionados, hemos recopilado la totalidad de los tuits que hacen uso de alguno de estos diez hashtags.

El trabajo que presentamos es de naturaleza exploratoria, interpretativa y cuantitativa, realizado desde una perspectiva pragmalingüística a partir del análisis del humor verbal. Este se lleva a cabo a partir de las interpretaciones inductivas del analista. Todos los textos, extraídos verbatim, fueron recopilados entre el 29 y el 30 de agosto de 2014 mediante la herramienta de analítica social Topsy Pro Analytics y conforman un corpus monolingüe, delimitado en la variedad diatópica del español peninsular, de aproximadamente 40.600 palabras. Para su análisis partimos de la TGHV, ya que esta propuesta ${ }^{12}$ «todavía hoy sigue siendo el punto de referencia de las investigaciones lingüísticas $y$ afines al humor $»^{13}$. Asimismo, para el estudio de las marcas e indicadores del humor verbal nos apoyamos en el modelo pragmático desarrollado por el grupo GRIALE ${ }^{14}$.

\section{Análisis del corpus}

La TGHV se basa en seis fuentes de conocimiento para la explicación del humor: la oposición de guiones, el mecanismo lógico, la situación, la meta, la estrategia narrativa y el lenguaje. A continuación, vamos a llevar a cabo el análisis de nuestro corpus de acuerdo con las fuentes mencionadas, lo que nos permitirá identificar distintas categorías de mensajes. Estas no son excluyentes. Además, la mayor parte de los tuits recopilados poseen un rasgo común: tienen como meta (es decir, como blanco de la burla) a políticos que han formulado declaraciones de carácter sexista, a los que se trata de ridiculizar. Sin

11. En este caso hemos comprobado que la búsqueda de dicha etiqueta en la que la primera letra de cada lexía aparece en mayúscula arroja también una gran cantidad de resultados, de ahí que hayamos decidido incluirla también en nuestro corpus.

12. ATTARDO, Salvatore y Victor RASKIN. «Script theory revis(it)ed: Joke similarity and joke representation model». Humor 4 (3-4) (1991), pp. 293-347.

13. RUIZ GuRILlo, Leonor. La lingüística del humor en español. Madrid, Arco/Libros, 2012, p. 24.

14. Cfr. Ruiz Gurillo, Leonor. Op. cit.; Ruiz GuRillo, Leonor y María Belén Alvarado ORTEGA. Irony and humor: from pragmatics to discourse. Ámsterdam, John Benjamins, 2013; Alvarado OrTega, María Belén y Leonor Ruiz GuRillo. Humor, ironía y géneros textuales. San Vicente del Raspeig, Publicaciones de la Universidad de Alicante, 2013, entre otros múltiples trabajos.

Feminismo/s 24, diciembre 2014, pp. 163-192 
embargo, no es este el caso de todos los tuits que hemos analizado. Por ejemplo, la etiqueta \#chochitodeoro no solo contribuyó a otorgar mayor difusión a los actos de amenaza hacia la imagen ${ }^{15}$ del político del BNG que dirigió tal comentario peyorativo a la vicepresidenta el Gobierno, sino que fue también incluida en una serie de tuits en los que se hacía uso del humor verbal para mofarse de ella,

Actor porno retirado (@OjeteAlmendra). «Soraya Saenz de Santamaria se gasta $40.000 €$ en el ginecólogo o en el veterinario? \#LaDuda \#ChochitoDeOro». 11-06-2013. Tuit.

y de otros miembros de su partido:

Gjavierescribano (@pacomontoyah).«Que quede claro que solo le pueden llamar \#chochitodeoro a soraya saez de santamaria su marido y el alcalde de Valladolid». 11-06-2013. Tuit.

Por otra parte, aunque las peculiares características de estos mensajes ${ }^{16}$ hacen que nos resulte muy difícil adscribirlos a un determinado género, como sucede con otros tipos de comunicación mediada por un dispositivo digital ${ }^{17}$, lo predominante son las secuencias de carácter argumentativo. No en vano, Twitter es utilizado por los internautas fundamentalmente para manifestar sus puntos de vista,

Pilar (@Pigomezsa).«\#chochitodeoro No me extraña que haya mujeres q se ofendan: el oro es muy poco acogedor. Me resisto a perder el humor por comentarios indignos». 12-06-2013. Tuit.

a veces con notables dosis de ironía:

Felipe Suárez(@FSuarez_Arosa). «Yo entiendo al alcalde de VALLADOLID, es un galán, un Paul Newman, quedan pocos en este país de pandereta \#EscracheDeSujetadores». 26-08-2014. Tuit.

Además, en los tuits que conforman nuestro corpus encontramos tanto secuencias descriptivas,

15. Brown, Penelope y Stephen C. LeVInSON. Politeness: Some universals in language usage. Cambridge, Cambridge University Press, 1978 [1987].

16. De carácter público y con una extensión limitada a los 140 caracteres.

17. Cfr. por ejemplo AlCÁntara Plá, Manuel. «Las unidades discursivas en los mensajes instantáneos de wasap». Estudios de Lingüística del Español 35 (2014), pp. 223-242. 


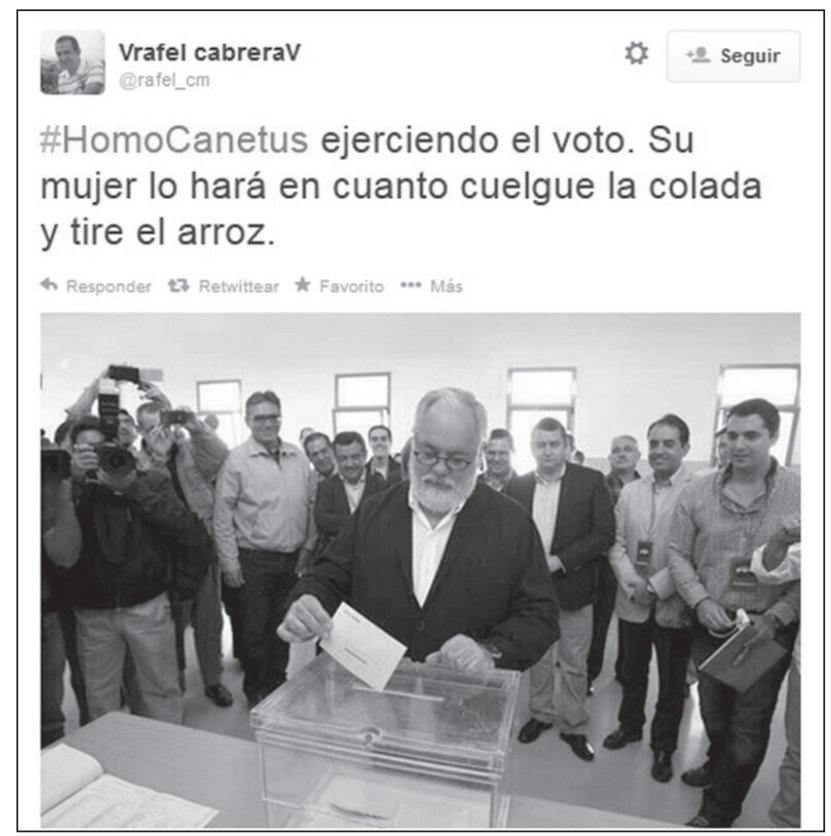

IMAGEN 5: Tuit publicado en el perfil de Twitter de Vrafel cabreraV (@rafel_cm) el 25-05-2014. Disponible en: <https://twitter.com/rafel_cm/status/470502952667729920/ photo/1>, consultado el 13-09-2014

como narrativas:

José G. Arribas (@HoTseChu). «Cuando le tiraron los sujetadores se oyó un estruendo de cadenas que se rompían \#EscracheSujetadores». 24-08-2014.

Tuit.

Y hay también mensajes que recrean la interacción conversacional. Como el siguiente, en el que se evoca el supuesto diálogo entre la líder de UPyD y un enajenado Toni Cantó que se niega a tomarse la medicación, lo que parece servir al internauta para explicar lo incongruente de sus declaraciones:

Marcos Torre (@MarcosTorre89). «Rosa Diez - «Toni te has tomado la pastilla?» - «No! La escupo» - «ahora entiendo...» \#tonicantofacts». 25-02-2013.

Tuit.

Tras estas precisiones sobre la diversidad de metas y de estrategias narrativas que pueden identificarse en los mensajes que conforman nuestro corpus, vamos a presentar la categorización de tuits que hemos llevado a cabo. 


\subsection{Tuits humorísticos sustentados en la oposición de guiones}

El planteamiento de la TGHV parte de la Teoría Semántica del Humor basada en guiones (Script-based Semantic Theory of Humor) (en adelante, TSHG) desarrollada en 1985 por Victor Raskin ${ }^{18}$. Según este autor, para poder considerar un texto como humorístico deben advertirse en él al menos dos guiones diferentes que se oponen entre sí a la manera de una relación antonímica, superponiéndose de forma parcial o total ${ }^{19}$. Por ejemplo, en los mensajes de Twitter que hacen uso de la etiqueta \#EscracheDeSujetadores resulta frecuente la identificación de esta prenda femenina con un arma, al ser exhibida para «agredir metafóricamente» al alcalde de Valladolid. De ahí que sea calificada como «peligrosa»,

Carlos Miguel Corral (@duenderepublica).«\#EscracheDeSujetadores todos los vehículos que van a Valladolid sin registrados, buscan a un peligroso sujetador escondido en una maleta». 24-08-2014. Tuit.

y que deba ser incautada por la guardia civil:

Lluís Ahicart (@lluisahicart).«La G.Civil de Valladolid incauta armas de feminizacion preparadas ataque coordinado ascensores \#EscracheDeSujetadores pic.twitter.com/tioEomphwj». 30-08-2014. Tuit.

Además, al guion sobre la violación en un ascensor evocado por De la Riva en sus declaraciones se opone el de la corrupción política en tuits como este, que equipara a los ediles con atracadores:

Paloma Lucas (@palomalhidalgo).«\#EscracheDeSujetadores Yo no subo en ascensores con alcaldes, porque en lugar de perder el sujetador perdería la cartera...». 24-08-2014. Tuit.

En estos mensajes los mecanismos lógicos ${ }^{20}$ se sustentan en relaciones sintagmáticas:

18. RASKIN, Victor. Semantic Mechanisms of Humor. Reidel, Dordrecht, 1985.

19. Cfr. Ruiz GuRILlo, Leonor. La lingüistica del humor... Op. cit. para una explicación más detallada de la que podemos realizar aquí.

20. Cfr. la taxonomía de los mecanismos lógicos elaborada por ATTARDO, Salvatore, HEMPELMANN, Christian F. y Sara Di MAIO. «Script oppositions and logical mechanisms: Modelling incongruities and their resolutions». Humor 15-1 (2002), pp. 3-46, y su aplicación al análisis de un conjunto de chistes en español llevada a cabo por Ruız GuRILLO, Leonor. La lingüística del humor... Op. cit. Existe un cierto debate sobre la necesidad o no de tener en cuenta los mecanismos lógicos en la comprensión del humor. A juicio de Christie Davies: «Meanings within texts derive from external social contexts and cognitive processing happens within that bundle of cells, chemicals and electrical exchanges, the brain. There is a real and material world out there and logical mechanisms cannot be studied in isolation from it, nor can the properties of that 
Sergio \#SiSePuede (@310Sergio). «Los toros se ofrecen a que los maten en la plaza para no sufrir el acoso de sus vacas según \#ToniCantóFacts». 26-022013. Tuit.

El internauta juega aquí con la yuxtaposición de dos de los temas sobre los que acababa de pronunciarse Toni Cantó: el supuesto acoso que reciben los hombres por parte de determinadas mujeres, por un lado, y la defensa de las corridas de toros, por otro. Estos dos guiones se oponen de forma que se atribuyen al astado decisiones humanas.

Además, algunas relaciones sintagmáticas se basan en relaciones espaciales directas que se apoyan en un paralelismo, como el que conlleva la dilogía del verbo comer en el siguiente tuit:

Lendakari (@natxox). «Comerle el \#chochitodeoro a la vice y morir por ingestión de metales pesados». 11-06-2013. Tuit.

Mensajes como el anterior, de naturaleza soez, difícilmente pueden comprenderse si el internauta no se encuentra al tanto de la actualidad noticiosa que ha motivado el surgimiento de una determinada etiqueta. De ahí que hayamos considerado necesario dedicar las primeras páginas de este artículo a la explicación de la situación que motiva la publicación de cada hashtag, pues su conocimiento resulta imprescindible para comprender los textos humorísticos y sus inferencias.

Entre los indicadores ${ }^{21}$ del humor más frecuentes en este tipo de mensajes se encuentran también figuras retóricas como la de la prosopopeya, que lleva a atribuir acciones propias de seres humanos a objetos inanimados,

Carlota Muñoz (@Carlotilla2). «Abrir mi cuenta y que me asalten miles de sujetadores... Pues buenos días y \#escrachesujetadores, hombre por favor!». 23-08-2014. Tuit.

o a animales de diversa naturaleza:

world bein ferred from humor theories or indeed literary or political theories. The authors have tried to meet my doubts about logical mechanisms but instead have made me doubt humor theory in general. Do not push GVTH too hard; words consisting entirely of consonants do not necessarily imply the deity». DAVIES, Christie. «Logical mechanisms: A critique». Humor 24, número 2 (2011), pp. 159-165, p. 165. Asimismo, resultan de gran interés los otros trabajos publicados en el volumen 24 (número 2) de la revista Humor, a raíz de que se cumplieran en 2011 veinte años del surgimiento de la TGHV.

21. Los miembros del grupo GRIALE diferencian entre los conceptos de marca e indicador atendiendo a su función. Así, las primeras poseen un valor procedimental, ya que ayudan a identificar el humor, mientras que los indicadores contienen humor en sí mismos. 
Víctor Suárez (@Victor_Suarez). «Los toros ponen denuncias de maltrato falsas \#ToniCantóFacts». 25-02-2013. Tuit.

Y los ejemplos de comparaciones y metáforas zoomórficas pueden multiplicarse con facilidad:

Calpurnio (@Calpur100).«Cañete como un gorila ante el monolito del conocimiento. Pero no es un monolito, es un canapé gigante. \#HomoCañetus». 20-05-2014. Tuit.

Quique Muela (@whomples). «Cañete Bravo http://pocket.co/svrV9 \#HomoCanetus se convierte en \#HomoAvestruz». 21-05-2014. Tuit.

\subsection{Tuits humorísticos basados en razonamientos imperfectos de carácter hiperbólico}

Por otra parte, los mecanismos lógicos que intervienen en la resolución del humor en muchos de los mensajes que conforman nuestro corpus se fundamentan en razonamientos imperfectos de carácter hiperbólico, como el que lleva a otorgar una fuerza destructiva a un sujetador,

José G. Arribas (@HoTseChu). «Cuando le tiraron los sujetadores se oyó un estruendo de cadenas que se rompían \#EscracheSujetadores» ${ }^{22}$. 24-08-2014. Tuit.

o el que exagera la actitud despreciativa de Miguel Arias Cañete hacia las mujeres:

Sergio Beecher (@Sergiano93). «Cañete ha visto a una mujer en un colegio electoral y ha pensado que era la que limpiaba. \#HomoCañetus \#EleccionesEuropeas». 25-08-2014. Tuit.

Véase también el siguiente mensaje, en el que tras la etiqueta en la que el eslogan del PP durante la campaña de las elecciones europeas presenta sus lexías fusionadas se introduce un sintagma nominal que da pie a un razonamiento imperfecto basado en una exageración:

ZERO (@CorrupcionZero).«\#LoQueEstaEnJuegoEs MI BOCATA DE CHORIZO \#MejorCiudadDeTapas \#HomoCañetus \#VotaAOtros \#votaamono pic. twitter.com/uiJoWPZhxj». 20-05-2013. Tuit.

22. Advertimos en este mensaje ciertas reminiscencias literarias, como este conocido verso de Garcilaso de la Vega: «En el silencio solo se escuchaba un susurro de abejas que sonaba». La estructura sintáctica del complemento directo es idéntica, así como el propósito de producir una aliteración y evocar el sonido correspondiente dando lugar a la figura retórica conocida con el nombre de paronomasia. También puede encontrarse cierta similitud con el conocido microrrelato de Augusto Monterroso: «Cuando despertó, el dinosaurio todavía estaba allí». 
El uso de las mayúsculas revela una aserción intensificada que la competencia pragmática del lector será capaz de atribuir a Arias Cañete, del que los internautas hacían mofa constante a causa de sus gustos gastronómicos. Por lo tanto, las mayúsculas actúan aquí como marcas que ayudan a identificar el humor.

Y lo mismo podría decirse de las comillas que podemos encontrar en el siguiente mensaje, que remite al enlace de una noticia que informa sobre el hecho de que tras las polémicas declaraciones de Miguel Arias Cañete durante el debate con Elena Valenciano, la imagen del candidato popular fuera prácticamente suprimida de la propaganda sobre el próximo mitin de su partido:

Salvador Faus Verdú (@SFausVerdu). «El PP 'esconde' a \#HomoCañetus en el Mitin de Valencia http://www.levante-emv.com/comunitat-valenciana/2014/05/21/pp-esconde-canete-mitin-valencia/1114662.html ... via @ levante_emv».21-05-2013. Tuit.

Por tanto, el uso de las comillas actúa aquí como clave de contextualización ${ }^{23}$ que ayuda a los lectores a recuperar el sentido cabal de dicho enunciado. Y es que los signos tipográficos y retóricos familiares a los lectores europeos no indican por sí mismos la ironía o el humor, pero adquieren esta propiedad en un contexto circunstancial, textual e intertextual específico ${ }^{24}$.

Además, en nuestro corpus hemos podido comprobar cómo determinados hashtags pueden actuar también como marcas del humor. Esto es lo que sucede con la etiqueta \#ToniCantóFacts en los siguientes mensajes,

LacrataZGZ (@LacrataRebel). «Los animales no tienen derechos, las denuncias por violencia de genero son falsas, el explotador Amancio Ortega es un heroe \#ToniCantoFacts». 31-05-2013. Tuit.

MAG (@MAGuisado).«Me parece fenomenal la propuesta de Toni Cantó de que las mujeres puedan también votar \#ToniCantófacts». 10-03-2013. Tuit.

donde dicho hashtag figura al final del tuit, y su presencia ayuda a disipar cualquier duda que pudiera albergar el lector sobre el carácter irónico o humorístico de su aserción previa, como explica este internauta:

23. GuMPERZ, John Joseph. Discourse Strategies. Cambridge, Cambridge University Press, 1982.

24. Hutcheon, Linda: «Poética de la ironía», en Pierre Schoentjes (ed.): La poética de la ironía, Madrid, Cátedra, 2003, pp. 241-250. 
Miky Gaza (@miky_co).«@MaGo_36 jajajaja... Mujer, cuando se pone el \#ToniCantoFacts o similar, ya se da por hecho que es cachondeo... xD». 12-02-2013. Tuit.

Por último, también podemos encontrar indicadores del humor en este tipo de mensajes, como la locución verbal abrir la boca, que en el siguiente tuit experimenta una desautomatización semántica ${ }^{25}$, al alterarse en cierta medida el significado de la unidad fraseológica original:

Max Pradera (@maxpradera).«El PP quiere que Cañete no abra ya la boca ni para comer. Será alimentado mediante una sonda. \#HomoCañetus». 20-052014. Tuit.

\subsection{Tuits con remates (punch lines) humorísticos}

El carácter humorístico de otro tipo de mensajes que conforman nuestra corpus no se hace patente hasta la lectura del miembro discursivo situado en último término. Este se asemeja a los remates (punch lines) con los que se cierran los chistes, pues producen en el lector ese mismo efecto inesperado. Véase la apódosis de la siguiente oración condicional:

J. L. Tamborino (@JTamborino). «Si pegan a las mujeres y matan a los toros, es porque antes...algo harían...\#ToniCantóFacts». 26-02-2013. Tuit.

El humor en tales tuits se basa en razonamientos imperfectos que se sustentan en conocimientos compartidos. Por ejemplo, en el siguiente mensaje, al enunciado inicial en el que se hace alusión a la victoria del Partido Popular en las elecciones europeas se le yuxtapone otro en modalidad exclamativa cuya intencionalidad humorística solo puede ser cabalmente interpretada por aquellos internautas que recuerden unas declaraciones formuladas por Miguel Arias Cañete en enero de 2013, durante su etapa al frente del Ministerio de Agricultura, Alimentación y Medio Ambiente, con las que instaba al consumo de yogures caducados basándose en que, a su juicio, no suponían un grave perjuicio para la salud:

25. TimofeEva, Larissa: «Las unidades fraseológicas», en Leonor Ruiz Gurillo y Xosé Antonio Padilla García (eds.): Dime cómo ironizas y te diré quién eres. Una aproximación pragmática a la ironía, Fráncfort, Peter Lang, 2009, pp. 193-217. 


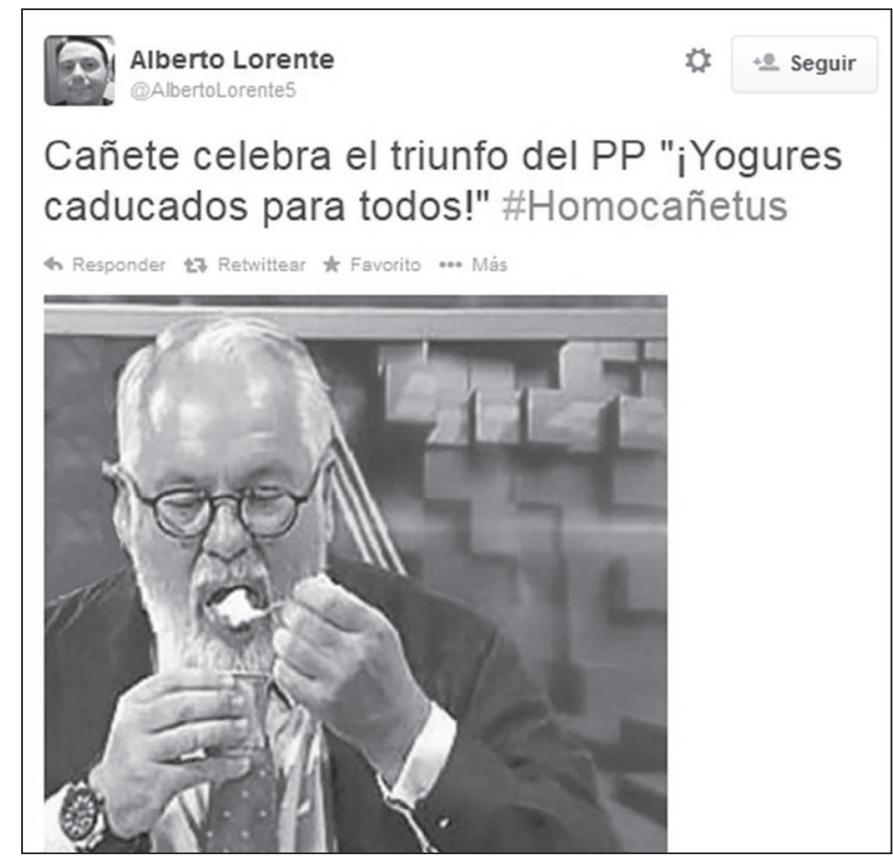

IMAGEN 6: Tuit publicado en el perfil de Twitter de Alberto Lorente (@AlbertoLorente5) el 27-05-2014. Disponible en: <https://twitter.com/AlbertoLorente5/ status/471362213182459904>, consultado el 12-09-2014

\subsection{Tuits humorísticos con apoyatura de imagen}

En mensajes multimodales como el anterior, o como el que mostramos a continuación, los guiones conviven en un mismo espacio discursivo ${ }^{26}$, ya que el texto publicado en el tuit remite a un contexto político cuyo carácter humorístico solo puede comprenderse al contemplar la fotografía que lo acompaña:

26. Padilla, Xosé Antonio y Elisa GiRonZeTti: «Humor e ironía en las viñetas cómicas periodísticas: un estudio pragmático-intercultural», en María Elena Placencia y Carmen García (eds.): Pragmática y Comunicación Intercultural en el mundo hispanohablante, Ámsterdan, Rodopi, 2012, pp. 93-133. 


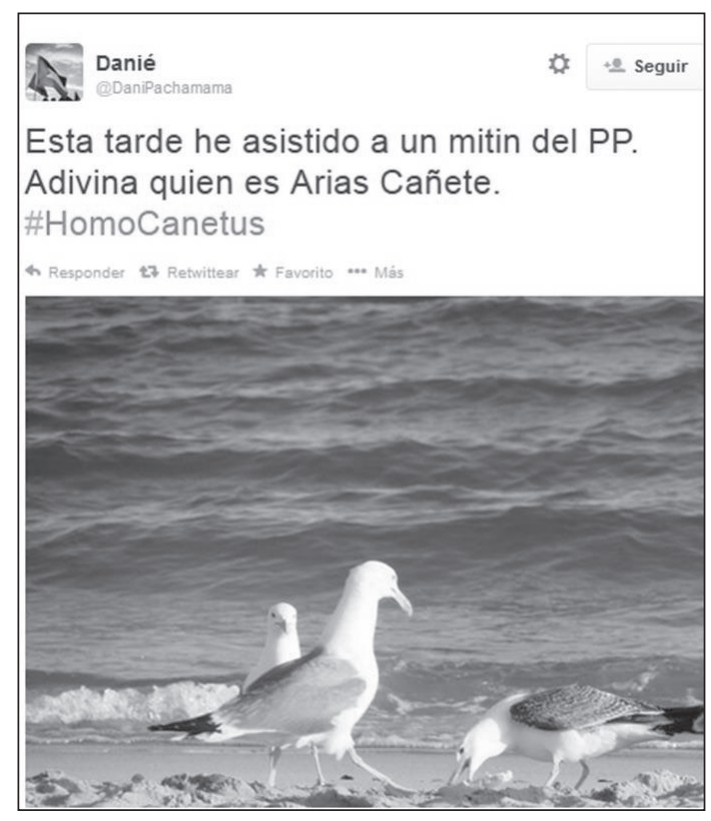

IMAGEN 7: Tuit publicado en el perfil de Twitter de Danié (@DaniPachaMana) el 16-052014. Disponible en: <https://twitter.com/DaniPachamama/status/468858811672186882/ photo/1>, consultado el12-09-2014

Este tipo de chistes se encuentran supeditados a la vigencia de un determinado hecho noticioso y dependen en gran medida de los conocimientos compartidos entre el autor y su modelo de audiencia. Por ejemplo, es posible que la afición por la gastronomía del candidato del PP a las elecciones al Parlamento Europeo no sea conocida por una buena parte de la sociedad española, para la que la interpretación de la imagen 7 resultará incompleta (aunque no sea errónea del todo). Y es que para la comprensión del humor es preciso contar con una triple competencia por parte del lector ${ }^{27}$. Así, su competencia genérica le permitirá identificar el mensaje como perteneciente al género de la parodia. Por otra parte, sus competencias lingüística e ideológica lo harán capaz de interpretar adecuadamente la fotografía de las aves que constituyen el símbolo del Partido Popular, y de descifrar en conjunción con

27. HutCHEON, Linda. «Ironie, satire, parodie, une approche pragmatique de l'ironie». Poétique 46 (1981), pp. 141-155. 
esta imagen el sentido implícito ${ }^{28}$ de las palabras que conforman el discurso proferido, en las que se infiere una velada alusión a la supuesta afición por la comida de Miguel Arias Cañete. También en la interpretación del siguiente tuit se hace necesaria una «competencia pragmático-comunicativa solvente, recompensada con el placer que produce descubrir los sentidos implícitos suscitados por el locutor ${ }^{29}$ :

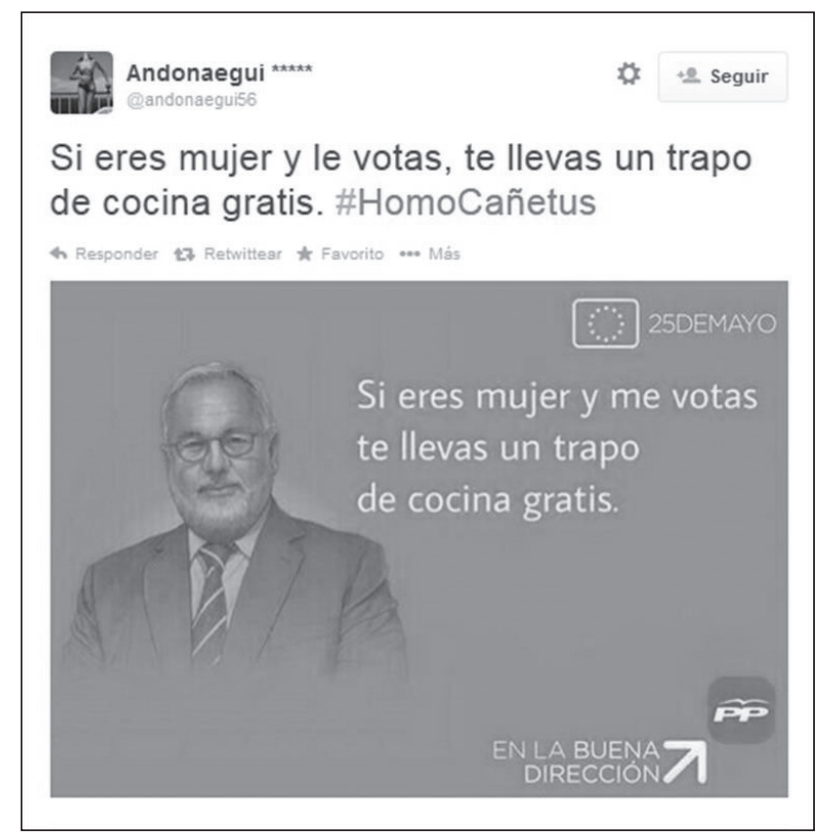

IMAGEN 8: Tuit publicado en el perfil de Twitter de Andonaegui (@andonaegui56) el 16-05-2014. Disponible en: <https://twitter.com/andonaegui56/ status/470120750209576960/photo/1>, consultado el 12-09-2014

Además, lo incongruente de este mensaje en el que se hace uso de la modalidad de intimación para pretendidamente recabar el voto femenino supone una ruptura en la isotopía discursiva, pues lo esperable en los

28. Cfr. también la teoría de la manifestación implícita de UTSUMI, Akira. «Verbal irony as implicit display of ironic environment: Distinguishing ironic utterances from non irony». Journal of Pragmatics 32 (2000), pp. 1777-1806.

29. MÉNDEZ GARCÍA DE PAREDES, Elena: «Humor y televisión en España», en Philippe Merlo y Begoña Riesgo (coords.): L'humour hispanique, Lyon, Université Lumière, vol. 1, 2003, pp. 149-189, p. 154. 
eslóganes electorales como el que se parodia no son las ofertas de obsequios, algo más propio del discurso publicitario. Por tanto, nos encontramos ante una nueva oposición de guiones. Además, las palabras del internauta parecen presentarse como muestras de «heterogeneidad enunciativa mostrada $»^{30}$, al ser atribuidas implícitamente al candidato del Partido Popular mediante el uso de la primera persona del singular en la imagen que acompaña el tuit.

Adviértase también cómo las palabras finales de este otro tuit juegan con la dilogía del sustantivo botella en el contexto particular que se presenta en el enlace inicial, que remite a un vídeo donde puede verse a la alcaldesa de Madrid, Ana Botella, formulando unas declaraciones que podrían calificarse de incoherentes:

CHINASKI (@chinaski_00). «http://facebook.com/photo.php?v= 909551985726684 ... . . . Será por esto q \#HomoCanetus se considera superior intelectualmente a las mujeres? Esto se llama BOTELLA VACÍA \#ARV». 21-05-2014. Tuit.

El sintagma nominal que aparece intensificado implica una inversión del principio de Informatividad, de acuerdo con la reformulación llevada a cabo por el grupo GRIALE sobre la inversión de los principios de Stephen C. Levinson $^{31}$. Es decir, al ocasionar una situación humorística provocada por la multiplicación de referentes evoca tanto el nombre propio de la representante del PP, como la expresión paremiológica «ver la botella medio llena o medio vacía», al tiempo que sugiere que la capacidad oratoria de esta se había visto mermada a causa del alcohol.

\subsection{Tuits paródicos}

Existen también en esta red de microblogging numerosas cuentas-parodia, creadas por internautas anónimos que se apropian de la identidad de personajes de relevancia pública para criticarlos o reírse de ellos ante sus seguidores. La mayor parte de dichas cuentas tiene una media de entre 100 y 250.000 seguidores, lo que unido a la difusión muchas veces viral de algunos de sus mensajes, que son retuiteados o reenviados regularmente de unas cuentas a

30. AuthiER-RevUZ, Jacqueline. «Hétérogénéité montrée et hétérogénéité constitutive: éléments pour une approche de l'outre dans le discourse». DRALAV 26 (1982), pp. 91-151.

31. LeVInSOn, Stephen C. Presumptive Meanings. The Theory of Generalized Conversational Implicature. Cambridge, Massachusetts, 2000. 
otras, indica que estas tienen un fuerte impacto en la red social. Como se indica en la página web de Twitter ${ }^{32}$, la suplantación de identidad o la creación de cuentas que fingen ser de otra persona con el fin de confundir o engañar es, en principio, una infracción de las reglas de la compañía. No obstante, de acuerdo con la Política de Suplantación de Identidad de la misma, sí está permitido crear cuentas parodia si el nombre de usuario difiere del nombre del sujeto parodiado, si la cuenta se distingue con un calificativo como no soy, falso o admirador, y si en el perfil se indica claramente: «Esto es una parodia» o «Cuenta de Parodia». Por ejemplo, el nombre de la alcaldesa de Valencia, Rita Barberá, se confunde premeditadamente con el de un conocido estudio de animación norteamericano en este perfil, desde el que se publican mensajes que parodian su manera de expresarse:

Rita Hanna Barbera (@truita_barbera). «No os metaís con Toni Cantó, joder... que a mí me dió clases de valenciano, vale?:-(\#tonicantofacts». 10-09-2011. Tuit.

Y hasta el álter ego de la ex presidenta de la Comunidad de Madrid, Esperanza Aguirre, recurre a la etiqueta \#EscracheSujetadores para mostrar su actitud crítica hacia las declaraciones del alcalde de Valladolid:

Esppeonza (@EsppeonzAguirre). «\#EscracheSujetadores nuevo modelo con cierre delantero para que sea mas fácil arrancarlo señor Alcalde pic.twitter. com/IIhq57Gjle». 22-08-2014. Tuit.

Alice Marwick y Danah Boyd ${ }^{33}$ proponen el concepto de contexto colapsado para explicar cómo Twitter engloba numerosas identidades en una sola, ya que la mayor parte de los usuarios de esta red social administran distintos perfiles a la vez, usando seudónimos y apodos y creando fakesters, es decir, cuentas en las que el autor simula ser un personaje célebre, con el objetivo de ocultar su propia identidad o adaptarse a distintos roles sociales ${ }^{34}$.

32. Disponible en: <https://support.twitter.com/articles/72692-pol-xed-tica-de-usurpaci-xf3-n-de-identidad>. Última consulta: 05-10-2014.

33. MARWICK, Alice y Danah BOYD. «I tweet honestly, I tweet passionately: Twitter users, context collapse, and the imagined audience». New Media \& Society 13 (1) (2010), pp. 114-133.

34. Un estudio más detallado acerca del uso humorístico de las cuentas parodias podemos encontrarlo en PANO ALAMÁN, Ana y Ana MANCERA RUEDA. «Identidades falsas y cuentas parodia en Twitter: análisis de la ironía y del humor verbal». Discurso y sociedad (en prensa). 


\subsection{Tuits irónicos}

Para Robert Escarpit ${ }^{35}$, uno de los recursos prototípicos del humor es la ironía. Si bien, es preciso tener en cuenta que, como hace notar Salvatore Attardo $^{36}$, hay ejemplos de ironía que no pueden considerarse en modo alguno humorísticos. Como el siguiente, donde un internauta dirige una apelación directa a la vicepresidenta del Gobierno en la que se sirve de un cuantificador indefinido:

El japonés (@_El_japones).«Sí señora, eso es enfrentarse al sistema, contra los recortes despilfarro. $40.000 €$ en ginecólogo me parecen pocos \#chochitodeoro». 11-06-2013. Tuit.

En virtud del contexto compartido que le confiere el hashtag motivado por la situación comunicativa ya descrita anteriormente, los lectores serán capaces de interpretar este mensaje ateniéndose a una inversión del principio de Cantidad, por el que poco pasa a adquirir una interpretación de elevada magnitud escalar. No en vano, la ironía es «una contradicción de valores argumentativos» ${ }^{37}$, pues en un nivel primario el enunciado implica realizar una afirmación original de p, con apariencia de sinceridad asertiva, para significar realmente que no se está de acuerdo con ella. Según Alain Berrendonner ${ }^{38}$, la enunciación tiene un valor argumentativo ostensible gracias a los marcadores argumentativos del propio enunciado, pero en su interpretación pueden intervenir también leyes del discurso como la ley de la lítote, capaz de dotar a la enunciación de un valor argumentativo derivado. De ahí la paradoja argumentativa que implica todo enunciado irónico. En nuestro corpus esta se pone de manifiesto, por ejemplo, por medio de sufijaciones aumentativas susceptibles de actuar como indicadores de ironía de contradicción, como en el caso del sustantivo nivelazo, utilizado en el siguiente tuit para censurar las palabras de Miguel Arias Cañete que se reproducen a continuación:

35. ESCARPIT, Robert. El humor. Buenos Aires, EUDEBA, 1962.

36. ATtARDO, Salvatore: "On the pragmatic nature of irony and its rhetorical aspects», en Németh Eniko (ed.): Pragmatics in 2000: Selected Papers from the 7th International Pragmatics Conference (IPrA), Antwerp, 2001, pp. 52-66.

37. Berrendonner, Alain. Elementos de Pragmática Lingüística. Barcelona, Gedisa, 1987, p. 151.

38. Ibíd., p 152. 


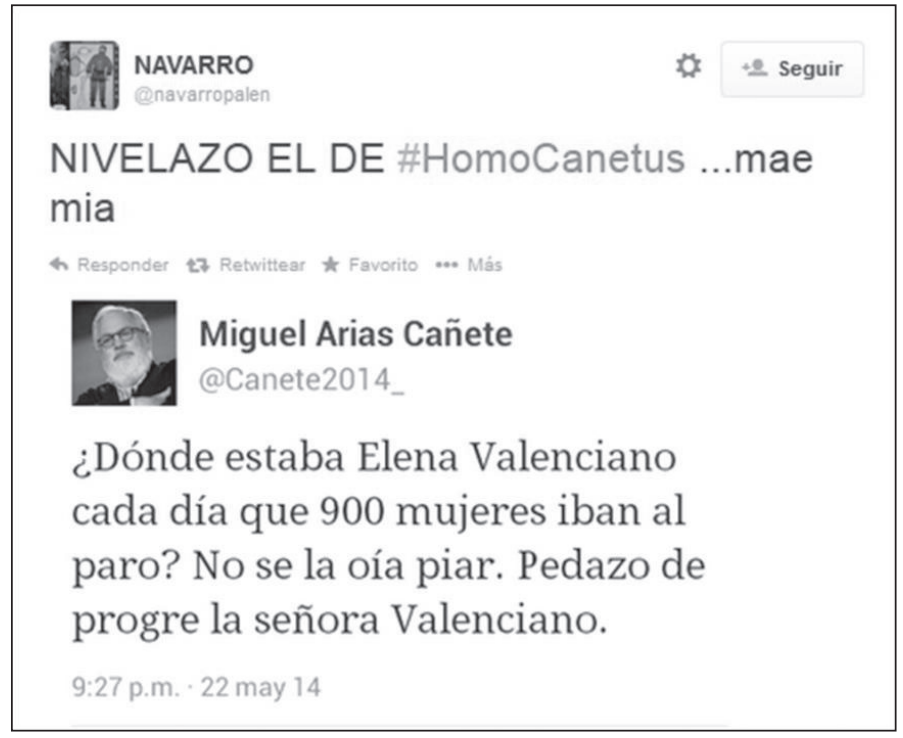

IMAGEN 9: Tuit publicado en el perfil de Twitter de Navarro (@navarropalen) el 22-052014. Disponible en: <https://twitter.com/navarropalen/status/469578936692006913/ photo/1>, consultado el 15-09-2014.

\section{Estudio cuantitativo}

Ya Nicholas Negroponte ${ }^{39}$ o Manuel Castells ${ }^{40}$ advirtieron del inmenso potencial que poseen las redes sociales para la democracia, debido a que la hiperconectividad que promueven permite construir conglomerados de relaciones, y descubrir patrones de pensamiento comunes. De hecho, según José Luis Orihuela $^{41}$, las redes sociales operan como un sistema sináptico que facilita la organización espontánea de sus participantes.

No extraña por tanto que los internautas recurran a Twitter para convocar un \#escrachedesujetadores ${ }^{42}$, para pedir la dimisión del presidente del Consejo General de la Ciudadanía en el Exterior mediante los hashtags \#dimisióncastelao o \#CastelaoDimision, o para calificar de \#machismoPSOE, \#machismoPP o \#MachismoARV las declaraciones sexistas de un político.

39. Negroponte, Nicholas. Being Digital. Nueva York, Knopf, 1995.

40. CASTElls, Manuel. La Galaxia Internet. Barcelona, Areté, 2001.

41. Orihuela, José Luis. Op. cit.

42. Esta idea «virtual» se plasmó también en una manifestación frente al consistorio vallisoletano, en la que las asistentes exhibieron sus sujetadores. 
Además, en ocasiones los usuarios de esta red de microblogging se sirven de la ironía o del humor para formular actos de amenaza hacia la imagen de sus representantes. Como puede apreciarse en la tabla que mostramos a continuación, en nuestro corpus esto resulta especialmente recurrente en el caso de las etiquetas \#ToniCantóFacts (donde el número de tuits que hacen uso de la ironía o del humor representa el $72,47 \%)$, \#chochitodeoro $(52,40 \%)$ y \#HomoCañetus (52,18\%):

TABLA 1: Cómputo de la presencia de mensajes que hacen uso de la ironía o el humor en el corpus analizado

\begin{tabular}{|c|c|c|c|c|c|}
\hline & $\begin{array}{l}\text { Número } \\
\text { total de } \\
\text { tuits }\end{array}$ & $\begin{array}{l}\text { Número de } \\
\text { mensajes } \\
\text { con alguna } \\
\text { muestra } \\
\text { de ironía o } \\
\text { humor }\end{array}$ & $\begin{array}{l}\text { Mensajes } \\
\text { humorísticos } \\
\text { publicados } \\
\text { desde } \\
\text { un perfil } \\
\text { masculino }\end{array}$ & $\begin{array}{l}\text { Mensajes } \\
\text { humorísticos } \\
\text { publicados } \\
\text { desde } \\
\text { un perfil } \\
\text { femenino }\end{array}$ & $\begin{array}{l}\text { Mensajes } \\
\text { humorísticos } \\
\text { publicados } \\
\text { desde un } \\
\text { perfil en el } \\
\text { que no puede } \\
\text { determinarse } \\
\text { la identidad } \\
\text { masculina o } \\
\text { femenina de } \\
\text { su autor }\end{array}$ \\
\hline \#escrachedesujetadores & 34 & $15(44,11 \%)$ & 4 & 10 & 1 \\
\hline \#EscracheDeSujetadores & 386 & $87(22,53 \%)$ & 24 & 50 & 13 \\
\hline \#HomoCañetus & 389 & $203(52,18 \%)$ & 98 & 38 & 67 \\
\hline \#ToniCantóFacts & 218 & $158(72,47 \%)$ & 104 & 17 & 37 \\
\hline \#dimisióncastelao & 140 & $12(8,57 \%)$ & 7 & 3 & 2 \\
\hline \#CastelaoDimision & 61 & $11(18,03 \%)$ & 6 & 1 & 4 \\
\hline \#chochitodeoro & 166 & $87(52,40 \%)$ & 52 & 13 & 22 \\
\hline \#MachismoARV & 36 & $7(19,44 \%)$ & 2 & 2 & 3 \\
\hline \#machismoPSOE & 22 & $3(13,63 \%)$ & 1 & 2 & 0 \\
\hline \#machismoPP & 74 & $17(22,97 \%)$ & 6 & 10 & 1 \\
\hline TOTAL & 1.526 & $600(39,31 \%)$ & $304(50,66 \%)$ & $146(24,33 \%)$ & $150(25 \%)$ \\
\hline
\end{tabular}

Nada extrañan estos datos si se tiene en cuenta que los hashtags \#ToniCantóFacts, \#chochitodeoro y \#HomoCañetus ya surgieron con la finalidad interpersonal de provocar la hilaridad entre los internautas. Y algo similar podría decirse de \#escrachedesujetadores $(44,11 \%)$ y \#EscracheDeSujetadores $(22,53 \%)$, etiquetas con las que se promovía una forma un tanto peculiar de protesta consistente en la exhibición de esta prenda interior femenina. No obstante, no es este el caso de \#machismoPP (22,97\%), \#MachismoARV 
(19,44\%), \#CastelaoDimision (18,03\%), \#machismoPSOE (13,63\%) y \#dimisióncastelao $(8,57 \%)$, surgidas preferentemente para mostrar el rechazo de los usuarios de esta red social por los comentarios denigrantes sobre las mujeres formulados por los políticos ya mencionados.

Por tanto, prima en los tuits que hacen uso de estas etiquetas la finalidad argumentativa, y solo en contados casos se pretende suscitar la risa. En tales ocasiones se hace uso de lo que podríamos considerar un humor subversivo que trata de sacar a la luz debilidades y contradicciones ocultas de las prácticas de poder ${ }^{43}$.

Dada la situación enunciativa que motiva la creación de este tipo de hashtags, surgidos para condenar la exhibición de machismo llevada a cabo por un político, cabría plantearse si son los internautas o las internautas los que más recurren a la ironía y al humor en sus mensajes. Como muestran los datos expuestos en la tabla precedente, creemos que los mensajes que mueven a la hilaridad fueron publicados en su mayoría por hombres (50,66\%), tal vez porque las mujeres se sienten más reacias a bromear sobre declaraciones en las que el sexo femenino es el principal referente. Así, solo el 24,33\% de los tuits con carácter humorístico parecen haber sido publicados por las internautas. Decimos parecen puesto que Twitter ofrece a sus usuarios la posibilidad de registrarse utilizando un perfil falso. Además, el 25\% de los mensajes de nuestro corpus en los que se hace uso del humor o la ironía han sido publicados desde cuentas como@piensomor o @Salitre_48, en las que no podemos realizar ninguna suposición sobre el sexo de quien se esconde tras ellas. Y, en general, las cifras que ofrecemos en la tabla 1 sobre la identidad masculina o femenina de los internautas no son más que meramente orientativas, por la posibilidad que ofrece esta red social de escribir desde el anonimato, adoptando un nombre de usuario sin correspondencia con la personalidad real.

\section{Conclusiones}

Basándonos en las seis fuentes en las que se sustenta la TGHV, en este trabajo hemos llevado a cabo un análisis de cómo los usuarios de Twitter se sirven de la ironía y del humor verbal para criticar a sus representantes políticos, a raíz de declaraciones o de la exhibición de comportamientos sexistas por parte de estos. Etiquetas como \#machismoPP, \#machismoPSOE, \#escrachedesujetadores o \#HomoCañetus contribuyen aquí a construir un marco cognitivo

43. BAJTín, Mijaíl. La cultura popular en la Edad Media y el Renacimiento. Madrid, Alianza Editorial, 1987.

Feminismo/s 24, diciembre 2014, pp. 163-192 
(en el sentido de George Lakoff ${ }^{44}$ ) que favorece la difusión de una contraargumentación respecto a las opiniones manifestadas por dichos políticos. No en vano, los hashtags no solo facilitan la clasificación de contenidos por su temática, sino que crean redes de mensajes y, por añadidura, de internautas que publican, leen y contestan a esos mensajes, llegando incluso a retuitearlos.

Para otorgar mayor difusión a sus críticas, los usuarios de esta red social realizan una serie de elecciones léxicas, gramaticales y fónicas, escogiendo de entre las diversas variables disponibles aquellas más apropiadas al contexto y a su finalidad interpersonal de divertir al lector, similares a las ya analizadas por Leonor Ruiz Gurillo ${ }^{45}$ a partir de la aplicación de los rasgos metapragmáticos propuestos por Jef Verschueren ${ }^{46}$. Tales elecciones son susceptibles de interpretarse como marcas e indicadores del humor verbal, al potenciar determinados mecanismos lógicos.

El estudio de cómo estos aspectos se plasman en nuestro corpus nos ha permitido identificar seis categorías distintas de mensajes, según pueda otorgárseles una interpretación humorística en virtud de una oposición de guiones, de su carácter hiperbólico, la existencia de un remate, o su naturaliza multimodal. Asimismo, hemos distinguido también entre tuits paródicos e irónicos. No obstante, de acuerdo con los resultados de nuestro análisis cuantitativo, el uso de los hashtags estudiados responde a una estrategia argumentativa encaminada a dañar la imagen pública de los líderes machistas, pero con la que no siempre se pretende suscitar la risa. Si bien, en los casos en los que prima tal intencionalidad humorística, parecen ser los hombres los que se decantan por este tipo de contenidos. Tal vez porque las mujeres se sienten más reacias a bromear sobre declaraciones en las que el sexo femenino es el principal referente. En cualquier dato, esta hipótesis no resulta fácil de demostrar, ya que la mayor parte de los internautas que publican sus mensajes en esta red social se escuda en el anonimato. Quizás porque, como han puesto de manifiesto Andreas H. Jucker ${ }^{47}$ o Seong-Jae $\mathrm{Min}^{48}$, la no revelación de la

44. LakofF, George. No pienses en un elefante: lenguaje y debate político. Madrid, Complutense, 2007.

45. RuIz GuRiLlo, Leonor. La lingüística del humor... Op. cit.

46. VersChUEREN, Jef. Para comprender la pragmática. Madrid, Gredos, 1999 [2002].

47. JUCKER, Andreas H. «Mass media communication at the beginning of the twenty-first century: Dimensions of change». Journal of Historical Pragmatics 4 (1) (2003), pp. 129-148.

48. Min, Seong-Jae. «Online vs. Face-to-Face deliberation: effects on civic engagement». Journal of Computer-Mediated Communication 12 (4) (2007). Disponible en: <http:// jcmc.indiana.edu/voll2/issue4/min.html>, consultado el 15-09-2014. 
identidad permite expresar la propia opinión de manera directa, al tiempo que propicia la comunicación desinhibida que mueve a la hilaridad.

\section{Referencias bibliográficas}

AlCÁNTARa Plá, Manuel. «Las unidades discursivas en los mensajes instantáneos de wasap». Estudios de Lingüística del Español 35 (2014), pp. 223-242.

Alvarado Ortega, María Belén y Leonor Ruiz Gurillo. Humor, ironía y géneros textuales. San Vicente del Raspeig, Publicaciones de la Universidad de Alicante, 2013.

ATTARDO, Salvatore: «On the pragmatic nature of irony and its rhetorical aspects», en Németh Eniko (ed.): Pragmatics in 2000: Selected Papers from the 7th International Pragmatics Conference (IPrA), Antwerp, 2001, pp. 52-66.

ATTARDO, Salvatore y Victor RASKIN. «Script theory revis(it)ed: Joke similarity and joke representation model». Humor 4 (3-4) (1991), pp. 293-347.

Attardo, Salvatore, Hempelmann, Christian F. y Sara Di MAIO. «Script oppositions and logical mechanisms: Modelling incongruities and their resolutions». Humor 15-1 (2002), pp. 3-46.

AuthIER-RevUZ, Jacqueline. «Hétérogénéité montrée et hétérogénéité constitutive: éléments pour une approche de l'outre dans le discourse». DRALAV 26 (1982), pp. 91-151.

BAjtín, Mijaíl. La cultura popular en la Edad Media y el Renacimiento. Madrid, Alianza Editorial, 1987.

Berrendonner, Alain. Elementos de Pragmática Lingüística. Barcelona, Gedisa, 1987.

Brown, Penelope y Stephen C. Levinson. Politeness: Some universals in language usage. Cambridge, Cambridge University Press, 1978 [1987].

CAstells, Manuel. La Galaxia Internet. Barcelona, Areté, 2001.

DAVIES, Christie. «Logical mechanisms: A critique». Humor 24, número 2 (2011), pp. 159-165.

ESCARPIT, Robert. El humor. Buenos Aires, EUDEBA, 1962.

GumPerz, John Joseph. Discourse Strategies. Cambridge, Cambridge University Press, 1982.

HUTCHEON, Linda. «Ironie, satire, parodie, une approche pragmatique de l'ironie». Poétique 46 (1981), pp. 141-155.

HutCheOn, Linda: «Poética de la ironía», en Pierre Schoentjes (ed.): La poética de la ironía, Madrid, Cátedra, 2003, pp. 241-250.

JUCKER, Andreas H. «Mass media communication at the beginning of the twentyfirst century: Dimensions of change». Journal of Historical Pragmatics 4 (1) (2003), pp. 129-148. 
LAKOFF, George. No pienses en un elefante: lenguaje y debate político. Madrid, Complutense, 2007.

LARA, Tíscar. «Twitter y sus funciones comunicativas». Tíscar.com, 13-02-2012. Disponible en: <http://tiscar.com/2012/03/11/twitter-y-sus-funciones-comunicativas/>, consultado el 15-09-2014.

LEVInSON, Stephen C. Presumptive Meanings. The Theory of Generalized Conversational Implicature. Cambridge, Massachusetts, 2000.

MARwiCK, Alice y Danah BoyD. «I tweet honestly, I tweet passionately: Twitter users, context collapse, and the imagined audience». New Media E Society 13 (1) (2010), pp. 114-133.

MÉNdez García DE PAREDES, Elena: «Humor y televisión en España», en Philippe Merlo y Begoña Riesgo (coords.): L'humour hispanique, Lyon, Université Lumière, vol. 1, 2003, pp. 149-189.

Min, Seong-Jae. «Online vs. Face-to-Face deliberation: effects on civic engagement». Journal of Computer-Mediated Communication 12 (4) (2007). Disponible en: <http://jcmc.indiana.edu/voll2/issue4/min.html>, consultado el 15-09-2014.

Negroponte, Nicholas. Being Digital. Nueva York, Knopf, 1995.

OriHuela, José Luis. Mundo Twitter. Barcelona, Alienta, 2011.

PAdilla, Xosé Antonio y Elisa GIRONZETTI: «Humor e ironía en las viñetas cómicas periodísticas: un estudio pragmático-intercultural», en María Elena Placencia y Carmen García (eds.): Pragmática y Comunicación Intercultural en el mundo hispanohablante, Ámsterdan, Rodopi, 2012, pp. 93-133.

PANO AlamÁn, Ana y Ana MANCERA RUEDA. «Identidades falsas y cuentas parodia en Twitter: análisis de la ironía y del humor verbal». Discurso y sociedad (en prensa).

RASKIN, Victor. Semantic Mechanisms of Humor. Reidel, Dordrecht, 1985.

RuIz Gurillo, Leonor. La lingüística del humor en español. Madrid, Arco/Libros, 2012.

Ruiz Gurillo, Leonor y María Belén Alvarado OrTega. Irony and humor: from pragmatics to discourse. Ámsterdam, John Benjamins, 2013.

TIMOFEEVA, Larissa: «Las unidades fraseológicas», en Leonor Ruiz Gurillo y Xosé Antonio Padilla García (eds.): Dime cómo ironizas y te diré quién eres. Una aproximación pragmática a la ironía, Fráncfort, Peter Lang, 2009, pp. 193-217. UTSUMI, Akira. «Verbal irony as implicit display of ironic environment: Distinguishing ironic utterances from non irony». Journal of Pragmatics 32 (2000), pp. 1777-1806.

VersCHUEREN, Jef. Para comprender la pragmática. Madrid, Gredos, 1999 [2002]. 